\title{
Trauma and violence in the Later Stone Age of southern Africa
}

\author{
Alan G Morris
}

Background. Antemortem and perimortem fractures in skeletons recovered from Later Stone Age burials in southern Africa demonstrate that people were, on occasion, the victims of severe trauma attributable to interpersonal violence.

Methods. Case studies are presented of cranial vault depression fractures on 4 different individuals and a young adult female who had 2 bone arrowheads embedded in the lower vertebrae. These are compared with other cases from the literature.

Results. The evidence from the archaeological skeletons suggests that interpersonal violence was a regular occurrence among prehistoric foragers. Additional cases show healed fractures of other bones, but these probably represent injuries from day-to-day activities rather than violent conflict.
Discussion. The ethnographic depiction of the San as 'harmless people' is probably inaccurate, or, at best, only representative of the situation in northern Botswana in the 1960s. Damage to the bones indicates that the cause of the trauma was intentional violence. Explanatory models that suggest intense competition between hunter-gatherer groups are probably more accurate than ones that suggest that the groups were non-aggressive.

Conclusion. Historical references to the San as aggressive and dangerous adversaries may be more accurate than revisionist historians have argued.
The presence of healed bone fractures in prehistoric skeletons is frequently noted in palaeopathological analyses. The identification of perimortem occurrences is less frequent, but elicits considerable interest because of the potential to shed light on fatal events. ${ }^{1}$

Traumatic bone lesions can be classified into those that occurred antemortem (with evident signs of healing), perimortem (without healing but with apparent signs of bone damage while still 'green') and postmortem (with signs of dry bone damage after soft-tissue decomposition). Bone-breaking trauma in living individuals includes violent acts, accidents, wear and tear and fractures secondary to bone disease. ${ }^{2,3}$ The timing of the breakage in the life of the individual has to be considered, in addition to the cause.

Case studies are presented of antemortem and perimortem fractures in skeletons recovered from Later Stone Age burials in southern Africa, demonstrating trauma attributable to interpersonal violence.

\section{Evidence of violence in the Later Stone Age (LSA) in South Africa}

Patterns of bone breakage in skeletal remains in archaeological sites in South Africa (SA), such as those studied by Morris in the Northern Cape and Pfeiffer on the Cape coast, ${ }^{4,5}$ are consistent with injuries caused by accidental trauma and suggest a low incidence of such trauma in these foraging groups. But, independent studies by Morris and Pfeiffer have noted 10 specific cases of antemortem and perimortem breaks consistent with violent rather than accidental trauma (Table 1). ${ }^{6,7}$

In order for a bone fracture to indicate intentional violence, it must be unlikely that it resulted from an accidental or disease process. Such confirmation is not possible for the bulk of postcranial breaks as evidence of the cause of a lesion is seldom unambiguous. Only one unambiguous case has been seen in SA,

Department of Human Biology, University of Cape Town Alan G Morris, $\mathrm{PhD}$

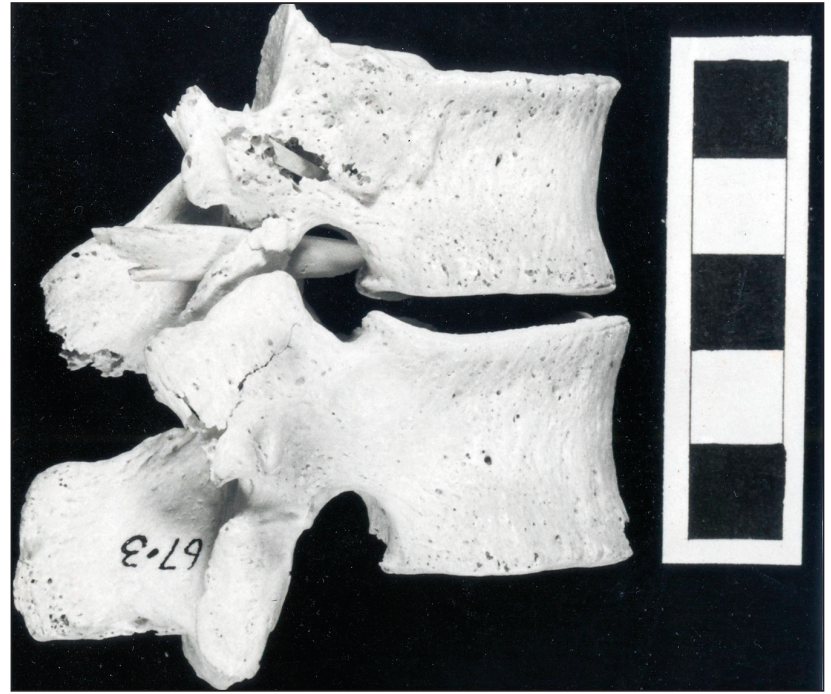

Fig.1. Lateral view of the 12th thoracic and 1st lumbar vertebrae of UCT 317 (Quoin Point) showing bone arrow-heads in situ.

where 2 arrow points remained embedded in the lower thoracic vertebrae of a young adult female from Quoin Point on the southern Cape coast (Fig. 1). ${ }^{8}$ Reconstruction of the event indicated that the victim was likely to have been lying on the ground in a prone position when the arrows were shot into her lower back. ${ }^{1,8}$ Although the exact cause of death could not be confirmed, the unhealed wounds suggested that death occurred soon after injury.

In contrast, cranial lesions provide solid evidence of violent intent when the nature of the impact point can be identified. In the cases described here, Pfeiffer noted that the punctured nature of the cranial lesions were indicative of impact with a pointed object such as a digging stick (unlike broader lesions characteristic of an object such as a falling rock or tree branch). ${ }^{7}$ Although such lesions could have been accidental, the context of the skeletons and their archaeological association tended to confirm non-natural injury.

The same pattern of non-natural injury is true for skeletons from Melkbosstrand and Modder River, where several individuals buried in shared graves demonstrated unhealed cranial lesions. ${ }^{9,10}$ A single grave in Melkbosstrand contained the remains of an adult woman 
Table 1. Cases of violent trauma from the Later Stone Age of South Africa

\begin{tabular}{lllll}
\hline Case & Sex & Age (years) & Location of wound & State of wound \\
\hline Quoin Point $^{8}$ & Female & $20-30$ & Thoracic vertebrae (embedded arrows) & Perimortem \\
Modder River $^{10}$ & - & $12-13$ & Cranial & Perimortem \\
& - & $6-7$ & Cranial & Perimortem \\
& - & $1-1.5$ & Cranial & Perimortem \\
Melkbosstrand & Female & Adult & Cranial & Perimortem \\
& - & $13-16$ & Cranial & Perimortem \\
Langklip $^{6}$ & Female & Adult & Cranial & Perimortem \\
Snuifklip $^{11}$ & Male & Old adult & Cranial & Antemortem \\
Andrieskraal $^{7}$ & Male & Old adult & Cranial & Antemortem \\
Whitcher's Cave $^{6}$ & - & Adult & Cranial & Antemortem
\end{tabular}

and a juvenile; both had gashes to the cranium consistent with a blow to the head with a linear instrument. ${ }^{9}$ Pfeiffer and van der Merwe reported the surprising discovery of the skeletons of 3 LSA children in the Modder River area; all bore cranial injuries inflicted with an instrument much like a digging stick, as opposed to a sharpedged implement, such as an arrow or a stone knife. ${ }^{10}$

A comparable case of perimortem injury was found at the site of Langklip near Hermanus on the southern Cape coast; the unpublished excavation of the remains of 8 individuals - currently stored in the Department of Human Biology at the University of Cape Town - was undertaken by F. Silberbauer in 1978. The burials in a partly calcified sand dune were recovered after disturbance, but postmortem breakages were readily visible and distinguishable from perimortem breaks. One healed vertebral arch fracture was evident on one of the recovered lumbar vertebrae. The partial cranium of an adult female presented evidence of perimortem damage, with a sharply depressed circular fracture, representing a small impact site on the right parietal on the quadrant nearest the bregma (Fig. 2). The striking similarity of this lesion to those noted by Pfeiffer and van der Merwe suggested trauma from a digging stick. ${ }^{10}$

Archaeological excavations on the southern Cape coast have revealed 3 cases of antemortem cranial injury in LSA foragers; all subjects survived their insults and lived for some time afterwards.

In the first case, an old man from Snuifklip was recovered from a consolidated sand dune at Vleesbaai, west of Mossel Bay; ${ }^{11} 2$ depressed fractures indicated that he had been hit over the head twice. Although one fracture had great potential to cause serious injury, the man survived, indicating that the brain and meninges were undamaged. Again, the lesions were similar to those caused by a digging stick or similarly shaped weapon. ${ }^{10}$

In the second case reported by Pfeiffer, antemortem injury was noted in an adult male skeleton from a cave at Andrieskraal in the Gamtoos Valley. ${ }^{7}$ The individual had a depressed healed fracture on the anterior-superior area of the right parietal bone, with cracks extending across both parietals and the frontal bone.

The third specimen, excavated in the 1930s from Whitcher's Cave near George, has not been described previously because of its fragmentary nature; previous work has concentrated on the more complete crania. Examination revealed a deeply depressed fracture on the inferior aspect of the right parietal. Subsequent healing had rounded the feature, confirming that the victim had survived the injury. Consistent with the aforementioned cases, the damage was noted to be highly localised. The impact site was rounded, although deeper anteriorly, suggesting impact from behind (Fig. 3).

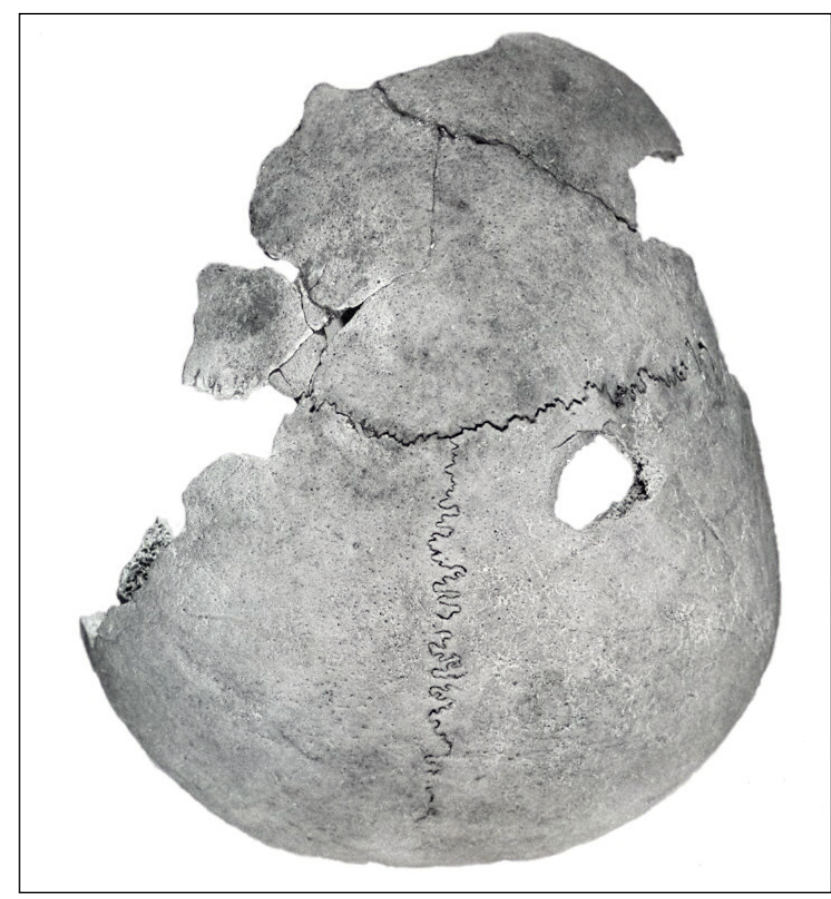

Fig. 2. Superior view of cranial vault of UCT 332 individual \#3 (Langklip) showing an injury on the right parietal just posterior to the coronal suture.

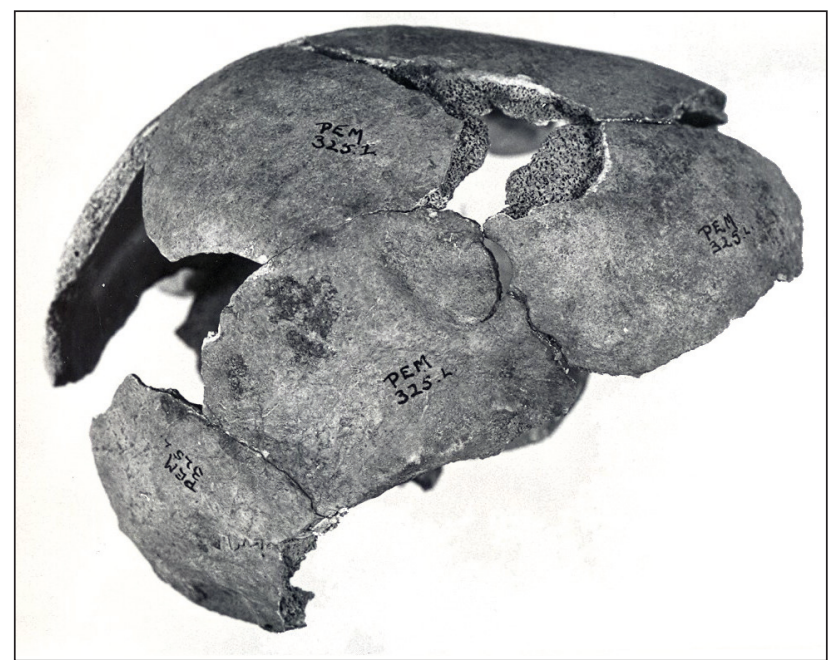

Fig. 3. Right lateral view of cranial vault of A1187 (Whitcher's Cave) showing a healed depressed fracture. 


\section{Discussion}

Ethnographic evidence for the Kalahari San has been used to argue that simple foraging communities were inherently peaceful and, wherever possible, avoided violence in their search for conflict resolution. ${ }^{12,13}$ Yet historical evidence and some ethnographic data suggest that violence was more common than previously assumed. Lee noted that violence among San groups focused on disputes over women, and he recorded a surprisingly large number of fatal interactions. ${ }^{14}$ If his data are statistically extrapolated, the murder rate among the Dobe Kung was greater than $30 / 100000$. This is 3 times higher than the New York City murder rate in the 1970s, and twice as high as the peak New York murder rate of $14.5 / 100000$ in $1990 .{ }^{15}$ It closely resembles the 2010 murder rate in Cape Town of 41.1/100 000, compared with an average global murder rate in the same year of $6.9 / 100000 .{ }^{16}$ However, crime statistics do not adequately explain the archaeological data. Where personal conflict is the motive, the overwhelming majority of deaths are of men, which is not the case in this data set of 10 individuals.

The death of the woman from Quoin Point is the least ambiguous case; the intention of the incident could only have been to kill. ${ }^{8}$ All ages and both sexes are represented in the described cases, with an apparent preponderance of females. Could these have been ritual murders? The children from Modder River were certainly too young to have been guilty of sexual or ritual transgressions, alluding to the idea that they were perhaps the victims of inter- rather than intragroup violence.

Humphreys has suggested that the rich linguistic tapestry of the Kalahari is inconsistent with territorial and band flexibility and, instead, indicates a long period of more rigid ethnic identity with language as a marker. ${ }^{17}$ Although gene flow between small forager populations is an obvious necessity to prevent inbreeding, the modern linguistic diversity suggests that either political or geographical separation of groups must have existed for a substantial period of time. Humphreys proposed that languages were markers of rigid territoriality among LSA foragers. The evidence of violence indicates that such territoriality was actively defended.

Osteological evidence of prehistoric violence supports a model where foraging groups did indeed behave in a manner inconsistent with the modern ethnographic model of the gentle San. However, much research remains to be done. Of greatest importance is the need to systematically gather as much information as possible concerning antemortem and perimortem fractures in the full set of LSA remains from different places and times in southern Africa.

Acknowledgements. I would like to acknowledge Susan Pfeiffer and Tony Humphreys for sharing ideas and data over the years. The Research Committee of the University of Cape Town financially supported this project.

1. Morris AG. Missing and Murderend. Cape Town: Zebra Press, 2011.

Lovell NC. Trauma analysis in paleopathology. Yearbook of physical anthropology 1997:40:139-170. 3. Lovell NC. Analysis and Interpretation of Skeletal Trauma. In: Katzenberg MA, Saunders SR, eds. Biological Anthropology of the Human Skeleton. 2nd ed. New Jersey: John Wiley \& Sons, 2008:341384

4. Morris AG. An Osteological Analysis of the Protohistoric Populations of the Northern Cape and Western Orange Free State, South Africa. PhD Thesis. University of the Witwatersrand, Johannesburg, 1984.

5. Pfeiffer S. The Health of Foragers: people of the Later Stone Age, Southern Africa. In: Cohen M, CraneKramer G, eds. Ancient Health: Skeletal Indicators of Agricultural and Economic Intensification. Gainesville: University of Florida Press, 2007:223-236.

6. Morris AG. Trauma and Violence in Later Stone Age South Africans. World Archaeology Congress 6, Dublin, 29 June - 4 July 2008.

7. Pfeiffer S. Cranial trauma as evidence of a stressful period among southern African foragers. In: Ellis CJ, Ferris N, Timmins PA, White CD, eds. The "Compleat Archaeologist": Papers in Honour of Michael W Spence. Occasional Publication of the London Chapter of the Ontario Archaeological Society 2010;9:227-237.

8. Morris AG, Parkington JE. Prehistoric homicide: a case of violent death on the Cape south coast, South 8. Morris AG, Parkington JE. Prehistoric homicide: a case of
Africa. South African Journal of Science 1982;78:167-169.

9. Pfeiffer S, van der Merwe NJ, Parkington JE, Yates R. Violent human death in the past: a case from the Western Cape, South Africa. South African Journal of Science 1999;95:137-140

10. Pfeiffer S, van der Merwe NJ. Cranial injuries to Later Stone Age children from the Modder River Mouth, Western Cape Province, South Africa. South African Archaeological Bulletin 2004;59(180):5965.

1. Morris AG, Thackeray AI, Thackeray JF. Late Holocene human skeletal remains from Snuifklip, near Vleesbaai, southern Cape. South African Archaeological Bulletin 1987;42:153-160.

12. Draper P. The Learning Environment for Aggression and Anti-Social Behavior among the !Kung. In: Montagu A, ed. Learning Non-Aggression: The Experience of Non-Literate Societies. New York: Oxford University Press, 1978:31-58.

13. Bonta BD. Conflict resolution among peaceful societies: The culture of peacefulness. Journal of Peace Research 1996;33(4):403-420. [http://dx.doi.org/10.1177/0022343396033004003]

14. Lee R. The !Kung San: Men, Women and Work in a Foraging Society. Cambridge: Cambridge Lee R. The !Kung San:

15. The Disaster Center. New York Crime Rates 1960 to 2010. New York: The Disaster Center, 2010. http:// www.disastercenter.com/crime/nycrime.htm (accessed 31 January 2012).

16. United Nations Office on Drugs and Crime (UNODC). Global Study on Homicide. Geneva: UNODC, 2011.

17. Humphreys AJB. Behavioural ecology and hunter-gatherers: from the Kalahari to the Later Stone Age. South African Archaeological Bulletin 2007;62(186):98-103.

Accepted 15 March 2012.

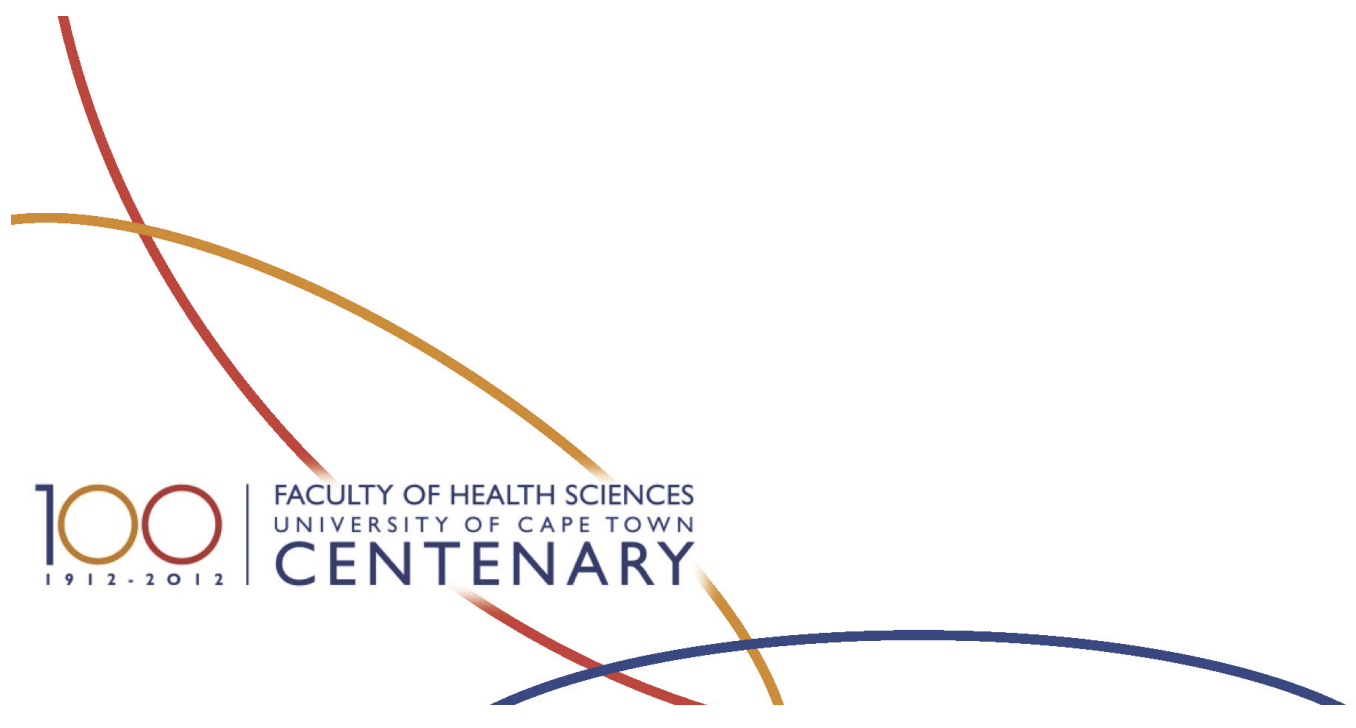

